\title{
ЭКОНОМИЧЕСКИЙ ПОДХОД К АНАЛИЗУ ПРИЧИН ПОЛИТИЧЕСКОГО КОНФЛИКТА НА УКРАИНЕ
}

\begin{abstract}
Аннотация: На рубеже 2013-2014 г. на Украине началась волна протестов, вызванная расхождениями политических сил на вектор внешнеполитического развития государства. Одна из сторон выступала за полную интеграцию с Евросоюзом, другая! за более тесные отношения с Россией. За несколько дней до подписания Украиной документов с Евросоюзом, правительство Украины приостановило подготовку к заключению этого соглашения. Это повлекло за собой недовольство сил, выступавших за Евроинтеграцию, переросших в острые протестные акции, направленные, главным образом, против правящей элиты. Результатом противостояния на Украине стало свержение действующей власти. В настоящей статье проведён обзор и анализ факторов внутри- и внешнеэкономического развития Украины. Проведён анализ развития реального и финансового секторов экономики. Анализ экономических параметров, а именно: структуры бюджета, торгового баланса, финансового состояния с точки зрения денежной структуры, соотношения иностранных и внутренних активов, векторов движения капитала Украины позволил обнаружить взаимосвязь между их динамикой и потенциальной угрозой стабильности государства.
\end{abstract}

Ключевые слова: дипломатия, политическая нестабильность, Украина, Россия, внешняя политика, международные отношения, экономика, нация, конфлликт, безопасность.

$\mathrm{M}$ ы являемся свидетелями непростых, весьма тревожных событий, происходящих сейчас на Украине, где социально-экономический кризис перерос в острейший внутриполитический конфликт. Ситуация резко усугубилась политическим вмешательством извне. Таким образом, внутренний кризис на Украине перерос, в конечном итоге, в сложный внешнеполитический конфликт. Градус напряжённости между сторонами конфликта постоянно возрастает. Риторика политиков - участников конфликта - становится всё более категоричной и жёсткой. По мнению автора данного исследования, одной из причин рассматриваемого конфликта является сбой в системе экономических взаимоотношений между его участниками: Украиной, Европейским Союзом, Россией, США. Важность исследования причин данного политического конфликта неоспорима вследствие того, что Россия является в нём не просто сторонним наблюдателем, а представляет и защищает свои экономические и геополитические интересы. Анализу экономических причин политического конфликта на Украине посвящено данное исследование.

Украина - государство в Восточной Европе. Столица - Киев. Население, по данным национальной государственной службы статистики на 1 ноября 2013 года, составляет 45447000 человек. Площадь территории Украины около 603 $549 \mathrm{kм}^{2}$; занимает 30-е место в мире по числен- ности населения, 44-е по территории и второе после России- по территории среди европейских стран $^{1}$.

Политическое устройство - унитарное государство, парламентско-президентская республика. Подразделяется на 27 административно-территориальных единиц, 24 из которых являются областями, 1 - автономной республикой и 2 представляют собой города государственного подчинения Киев и Севастополь².

На юге омывается Чёрным и Азовским морями. Имеет сухопутную границу Россией, Белоруссией, Польшей, Словакией, Венгрией, Румынией и Молдавией.

До 1996 г. Украина располагала третьим по величине стратегическим ядерным запасом после США и России.

Украина - индустриально-аграрная страна. Структура экономики широко представлена как различными отраслями промышленности - чёрной металлургией, химической, лесоперерабатывающей, пищевой промышленностью, так и разнообразными отраслями сельского хозяйства растениеводством, животноводством.

\section{Сайт Международного банка: www.worldbank.org}

На момент окончания исследования Крым и Севастополь, согласно результатам референдума и Указу Президента РФ, одобренному КС РФ и обеими палатами Парламента перешёл в состав России в качестве субъектов федерации. 
Революции / Revolutions

Таблица 1.

Ряд экономических показателей Украины за период с 2008 по 2013 г. *

\begin{tabular}{|l|c|c|c|c|c|c|}
\hline \multicolumn{1}{|c|}{ Показатель } & $\mathbf{2 0 0 8}$ г. & $\mathbf{2 0 0 9}$ г. & $\mathbf{2 0 1 0}$ г. & $\mathbf{2 0 1 1}$ г. & $\mathbf{2 0 1 2}$ г. & $\mathbf{2 0 1 3}$ г. \\
\hline ВВП, млрд. долл. & 180,0 & 117,2 & 136,4 & 165,2 & 184,1 & 206,1 \\
\hline ВВП, млрд. грив. & 1440 & 913 & 1.083 & 1.317 & 1.473 & 1.649 \\
\hline ВВП на душу населения, Тыс. долл. & 3.719 & 2.438 & 2.818 & 3.413 & 3.804 & 4.258 \\
\hline Темп изменения ВВП, \% & 5,2 & $-14,8$ & 4,1 & 5,2 & 3,0 & 3,5 \\
\hline
\end{tabular}

* Сайт Международного валютного фонда: www.imf.org

Таблица 2.

Показатели государственного бюджета Украины за период с 2008 по 2013 г. *

\begin{tabular}{|l|c|c|c|c|c|c|}
\hline \multicolumn{1}{|c|}{ Показатель } & $\mathbf{2 0 0 8}$ г. & $\mathbf{2 0 0 9}$ г. & $\mathbf{2 0 1 0}$ г. & $\mathbf{2 0 1 1}$ г. & $\mathbf{2 0 1 2}$ г. & $\mathbf{2 0 1 3}$ г. \\
\hline Доходы, млрд. грн. & 231,7 & 209,7 & 240,6 & 314,6 & 346,03 & 339,18 \\
Доходы, \% ВВП & 24,44 & 22,96 & 22,93 & 23,9 & 24,56 & 24,31 \\
\hline Расходы, млрд. грн. & 241,45 & 242,43 & 303,60 & 333,46 & 395,66 & 403,40 \\
Расходы, \% ВВП & 25,47 & 26,54 & 28,04 & 25,33 & 28,08 & 28,31 \\
\hline Баланс, млрд. грн. & $-12,5$ & $-35,6$ & $-64,3$ & $-23,56$ & $-53,39$ & $-64,70$ \\
Баланс, \% ВВП & $-1,32$ & $-3,89$ & $-5,94$ & $-1,79$ & $-3,79$ & $-3,90$ \\
\hline
\end{tabular}

* Сайт министерства финансов Украины: minfin.gov.ua

Ключевые показатели, отражающие экономическое развитие Украины в период с 2008 по 2013 г. представлены в таблице 1 .

В таблице представлены следующие экономические показатели: ВВП, выраженный в долл. США по паритету покупательной способности и в национальной валюте, ВВП на душу населения, выраженный в долл. США. Кроме того, представлен темп изменения ВВП.

Как следует из таблицы 1 , характер изменения ВВП и ВВП на душу населения связан как с падением рассматриваемых величин в 2009 г., связанным с последствиями мирового экономического кризиса, так и с последующим ростом. К 2013г. ВВП Украины на душу населения составил 4.258 тыс. долл.

Потребности страны, подлежащие удовлетворению за счёт государственной казны, источники и размеры ожидаемых поступлений в государственную казну отражаются в важном финансовом документе - государственном бюджете. Важнейшие показатели бюджета Украины за период с 2008 по 2013 г. приведены в таблице 2 .

Как следует из представленной таблицы 2, структура бюджета Украины представлена статьями доходов, расходов и итоговым балансом.

В течение исследуемого периода доходы Украины имели слабо выраженную тенденцию кувеличению, нарушенную в 2009 г. заметным падением с 232 млрд. долл. в 2008 до 210 млрд. долл. К 2013 статья доходов составляла 339,18 млрд. долл.
Расходы Украины имели ярко выраженную тенденцию к увеличению в течение всего исследуемого периода.

Важно отметить, что с 2008 по 2010 г. баланс бюджета оставался дефицитным: расходы превышали доходы. Кроме того, дефицит государственного бюджета Украины непрерывно и неуклонно увеличивался. Небольшое уменьшение дефицита в 2011г. сменилось резким возрастанием его в последующие годы. К 2013 г. дефицит бюджета составлял около 65 млрд. долл., что соответствует почти 80\% от ВВП.

Результаты денежно-кредитной политика Украины в течение 2010-2013 гг. представлены в таблице 3.

В таблице 3 представлены следующие индикаторы: широкие деньги, состоящие из чистых иностранных активов (ЧИА), чистых внутренних активов (ЧВА).

Как следует из представленной таблицы, величина широких денег в течение указанного периода стабильно возрастает с 597,87 до 881,962 млрд. грн.

Что касается объёма ЧИА, то данный параметр имеет явную тенденцию к понижению: с 62,043 до 37, 237 млрд. грн. В свою очередь, объём ЧВА имеет явную тенденцию к повышению: с 535,826 до 791,549 млрд. грн.

Весьма примечательным является пункт «Вложения в экономику», входящий в состав ЧВА. Как 
Международные отношения / International Relations

Таблица 3.

Денежный обзор Украины за период с 2010 по 2013 г.*

\begin{tabular}{|l|c|c|c|c|}
\hline \multicolumn{1}{|c|}{ Показатель, млрд. грн. } & $\mathbf{2 0 1 0}$ г. & $\mathbf{2 0 1 1}$ г. & $\mathbf{2 0 1 2}$ г. & $\mathbf{2 0 1 3}$ г. \\
\hline Чистые иностранные активы & 62,043 & 60,968 & 36,625 & 37,237 \\
\hline Чистые внутренние активы (всего) & 535,826 & 624,547 & 688,686 & 791,549 \\
Внутренний кредит, & & & \\
из которого & 858,853 & 969,579 & $1.022,288$ & $1.126,867$ \\
Кредит правительству & 114,98 & 151,757 & 188,751 & 244,896 \\
Вложения в экономику & 743,843 & 764,7 & 833,537 & 881,962 \\
\hline Другие статьи & $-323,03$ & $-345,17$ & $-333,60$ & $-335,32$ \\
\hline Широкие деньги & 597,87 & 661,054 & 725,311 & 828,786 \\
\hline
\end{tabular}

* Сайт Международного валютного фонда: www.imf.org

следует из представленной таблицы, объём вложений в экономику Украины со стороны государства непрерывно увеличивается с 743,843 до 881,962 млрд.грн.

Вместе с тем, особого внимания заслуживает пункт "Другие статьи". Как следует из представленных в таблице результатов, объём средств, представленных в указанном параграфе, во-первых, имеет отрицательное значение, во-вторых, имеет практически неизменное значение и составляет, в среднем, в абсолютном исчислении 335 млрд. долл. Кроме того, вызывает недоумение тот факт, что указанный параграф в отчёте МВФ остался нерасшифрованным, поскольку в нём отмечаются довольно крупные средства, например, превышающие ЧИА по абсолютной величине и составляющие около половины от ЧВА также по абсолютному значению. Отрицательные значения объёмов средств в пункте "Другие статьи" явно указывают на их отток из Украины.

Платёжный баланс Украины представлен в таблице 4.

Как следует из представленной таблицы 4, структура платёжного баланса представлена следующими пунктами: «Счёт текущих операций», «Финансовый и капитальный счёт», «Ошибки и пропуски», «Общий баланс». Также таблица содержит пункт «Финансирование дефицита платёжного баланса».

Рассмотрим более детально каждый из представленных параграфов.

Итак, «Счёт текущих операций» представлен статьями экспорта-импорта товаров и услуг.

Таблища 4.

Платёжный баланс Украины за период с 2005 по 2010 г*

\begin{tabular}{|c|c|c|c|c|c|c|}
\hline Показатель, млрд.долл. & 2008 r. & 2009 г. & 2010 r. & 2011 r. & 2012 r. & 2013 г. \\
\hline $\begin{array}{l}\text { Счёт текущих операций, } \\
\text { Экспорт товаров } \\
\text { Импорт товаров } \\
\text { Услуги (нетто) }\end{array}$ & & $\begin{array}{c}-1,7 \\
40,4 \\
-44,7 \\
2,4\end{array}$ & $\begin{array}{c}-3,0 \\
52,2 \\
-60,6 \\
4,4\end{array}$ & $\begin{array}{c}-9,0 \\
69,4 \\
-83,2 \\
4,9\end{array}$ & $\begin{array}{c}-4,5 \\
73,5 \\
-91,6 \\
6,0 \\
\end{array}$ & $\begin{array}{c}-15,0 \\
78,2 \\
-98,5 \\
4,9\end{array}$ \\
\hline $\begin{array}{l}\text { Финансовый и капитальный счёт } \\
\text { Счёт движения капитала } \\
\text { Финансовый счёт, из которого } \\
\text { прямые инвестиции (нетто) } \\
\text { портфельные инвестици (нетто) } \\
\text { другие инвестиции (нетто) }\end{array}$ & & $\begin{array}{c}-12,3 \\
0,6 \\
-12,9 \\
4,7 \\
-1,6 \\
-16,0\end{array}$ & $\begin{array}{c}6,3 \\
0,2 \\
6,1 \\
5,8 \\
4,3 \\
-3,9\end{array}$ & $\begin{array}{c}5,8 \\
0,1 \\
5,7 \\
7,0 \\
1,6 \\
-2,8\end{array}$ & $\begin{array}{c}6,9 \\
0 \\
6,8 \\
8,5 \\
2,2 \\
-3,3\end{array}$ & $\begin{array}{c}16,1 \\
0 \\
16,1 \\
9,0 \\
2,7 \\
4,4\end{array}$ \\
\hline Ошибки и пропуски & & 0,2 & 1,4 & 0,4 & 0,5 & 0 \\
\hline Общий баланс & & $-13,9$ & 4,7 & $-2,7$ & $-4,4$ & 1,1 \\
\hline $\begin{array}{l}\text { Финансирование дефицита платёжного баланса } \\
\text { Общие резервы (возрастание: «-») } \\
\text { Ресурсы МВФ (нетто) } \\
\text { Официальное финансирование, } \\
\text { из которого } \\
\text { Всемирный банк } \\
\text { Евросоюз } \\
\text { ЕБРР }\end{array}$ & & $\begin{array}{l}13,9 \\
5,7 \\
8,2 \\
0 \\
0 \\
0 \\
0\end{array}$ & $\begin{array}{r}-5,0 \\
-8,5 \\
3,4 \\
0,4 \\
0,2 \\
0,1 \\
0,1\end{array}$ & $\begin{array}{c}2,5 \\
2,5 \\
0 \\
0,3 \\
0,2 \\
0,1 \\
0,1\end{array}$ & $\begin{array}{c}3,9 \\
-6,4 \\
2,3 \\
0,5 \\
0,2 \\
0,1 \\
0,2\end{array}$ & $\begin{array}{c}-1,1 \\
4,6 \\
-5,6 \\
0 \\
0 \\
0 \\
0\end{array}$ \\
\hline
\end{tabular}

* Сайт Международного валютного фонда: www.imf.org 
Значение счёта текущих операций отрицательно в течение всего исследуемого периода, имеет тенденцию к снижению и составляет -1.7 млрд. долл.в 2009 г. и $-15,0$ млрд. долл. в

2013 г. Это связано с тем, что на протяжении всего исследуемого периода товарный импорт превышал экспорт; что касается сферы услуг, то в этом случае наблюдается обратная тенденция, однако чистый положительный объём экспорта услуг не компенсирует таковой в случае оборота товаров.

«Финансовый и капитальный счёт» представлен «Счётом движения капитала» и «Финансовым счётом», отражающим вектор инвестиционной активности Украины.

В течение исследуемого периода, объём средств, отражаемых в финансовом и капитальном счёте, изменяется, во- первых, с изменением знака, во-вторых, с тенденцией к увеличению. Так в 2009 г. объём средств на указанном счёте составляет -12.3 млрд. долл., а в 2013 г. уже +16,1 млрд. долл. Значения объёмов на счёте движения капитала, вопервых, положительны в течение исследуемого периода, во-вторых, относительно невелики, а в 2012 и 2013г. принимают нулевые значения.

«Финансовый счёт» представлен статьями «Прямые инвестиции», «Портфельные инвестиции» и «Другие инвестиции». В течение исследуемого периода «Финансовый счёт», во-первых, изменяется с инверсией знака, во-вторых, имеет тенденцию к увеличению. Соотношение объёмов средств, представленных пунктами «Прямые инвестиции», «Портфельные инвестиции» и «Другие инвестиции» является динамичным как по абсолютному значению, так и по знаку. Например, в 2009 г. значение объёма средств в пункте «Другие инвестиции» отрицательно, а доля указанного параграфа к объёму финансового счёта на указанный год максимальна по отношению к двум другим параграфам. В 2013 г. наблюдается иная ситуация: объём «Других инвестиций» положителен, а максимальную долю в пункте «Финансового счёта» занимают уже «Прямые инвестиции», объём которых в указанном году также положителен.

Как следует из представленной таблицы 4, общий платёжный баланс Украины за период с 2009 по 2013 г. отрицателен, кроме 2010 и 2013 г. Т.о., платёжный баланс Украины преимущественно дефицитен. В этой связи возникает необходимость финансирования дефицита платёжного баланса. Как следует из представленной таблицы, фин6ансирование дефицита платёжного баланса осуществляется путём использования следующих средств:

1) Использования общих резервов Украины; 2) Ресурсов Международного валютного фонда (МВФ); 3) Ресурсов Всемирного банка; 4) Ресурсов Европейского банка реконструкции и развития (ЕБРР); 5) Средств, предоставленных Евросоюзом.

Следует отметить, что совокупность всех представленных извне средств для финансирования дефицита платёжного баланса, кроме резервов Украины, весьма незначительны.

Исключением является лишь 2009 г., когда МВФ выделил Украине на покрытие дефицита платёжного баланса более половины необходимого объёма ресурсов.

Итак, нетрудно догадаться, что на выполнение государственных программ Украине собственных средств хватает не всегда. Попробуем разобраться с финансовыми обязательствами Украины, возникающими в связи с привлечением для выполнения государственных программ и заказов средств негосударственных организаций и населения страны. Подобные обязательства представляют собой не что иное, как государственный долг. Структура общего долга Украины за период с 2010 по 2014 г. представлена в таблице 5.

Таблица 5.

Структура общего долга Украины за период с 2010 по 2014 г*

\begin{tabular}{|c|c|c|c|c|c|}
\hline Показатель & 2010 г. & 2011 г. & 2012 г. & 2013 r. & 2014 г. \\
\hline $\begin{array}{l}\text { Общий государственный долг Украины, } \\
\text { млрд. долл. из которого: } \\
\text { Внешний долг, млрд. долл. } \\
\text { Темп изменения, \% }\end{array}$ & $\begin{array}{l}39,7 \\
26,5\end{array}$ & $\begin{array}{c}54,2 \\
34,8 \\
31,1\end{array}$ & $\begin{array}{c}59,2 \\
37,5 \\
7,8\end{array}$ & $\begin{array}{c}64,5 \\
38,7 \\
3,2\end{array}$ & $\begin{array}{l}73,2 \\
37,4 \\
-2,9\end{array}$ \\
\hline $\begin{array}{l}\text { Внутренний долг, млрд. долл. } \\
\text { Темп изменения, \% }\end{array}$ & 13,2 & $\begin{array}{l}19,5 \\
48,3\end{array}$ & $\begin{array}{l}21,7 \\
11,3\end{array}$ & $\begin{array}{l}25,8 \\
18,8\end{array}$ & $\begin{array}{l}35,8 \\
37,6\end{array}$ \\
\hline $\begin{array}{l}\text { Отношение } \\
\text { Внешний долг / Внутренний долг }\end{array}$ & 2,0 & 1,8 & 1,7 & 1,5 & 1,0 \\
\hline
\end{tabular}

* Сайт министерства финансов Украины: minfin.gov.ua 


\section{Международные отношения / International Relations}

Как следует из представленной таблицы, общий государственный долг Украины, в общем виде, состоит из внешнего и внутреннего долга. Как следует из представленных данных, общий государственный долг непрерывно увеличивается в исследуемый период: с 39,7 млрд. долл. в 2010 г. до 73,2 млрд. долл.

Внешний долг Украины составлял 26,5 млрд. долл. в 2010 г. и увеличивался непрерывно до 38,7 млрд. долл. в 2013 г. По состоянию на январь 2014 г., внешний долг Украины незначительно снизился до 37,4 млрд. долл.

Внутренний долг Украины непрерывно увеличивался с 13,2 млрд. долл. в 2010 г. до 35,8 млрд. долл. в 2014 г.

Следует отметить, что темп изменения внешнего долга Украины непрерывно и значительно уменьшался: в 2011 г. он составлял 31,1\%, а к 2014 г. его значение уже составило -2,9\%.

Что касается темпа изменения внутреннего долга, то его значение сначала снизилось с 48,3 \% в 2011 г. до 11,3 \% в 2012 г., а затем возрастало до $37,6 \%$ в 2014 г.

Рассмотрим величину, равную отношению величины внешнего долга к внутреннему. Экономический смысл этой величины состоит, очевидно, в том, что отражает нагрузку того или иного долгового инструмента в общем долге.

Важно отметить, что отношение объёмов внешнего долга к внутреннему долгу изменяется в течение исследуемого периода. Так, в 2010 г. оно составляет 2, а в 2014 г. уже 1 . При общем возрастании долга это свидетельствует о том, что оплата внешнего долга компенсируется только наращиванием внутреннего долга, не меняя сути долговой ситуации.

Итак, возрастание долга, совершенно очевидно, связано с несовершенством экономической модели Украины. Структурные экономические задачи в полном объёме не решались. Вместе с тем, указанные тенденции изменения компонент общего долга Украины свидетельствуют о том, что, во-первых, для финансирования экономики и государственных обязательств и программ Украине остро не хватало собственных средств. Во-вторых, требовалось постоянно привлекать как внешние, так и внутренние займы. В-третьих, выполнение обязательств по внешним займам проходило за счёт усиления долговой нагрузки, связанной с увеличением объёма внутреннего займа, ведь, кроме того, падение темпов роста внешнего долга шло наряду с увеличением темпов роста внутренних заимствований.

Очевидно, что подобная ситуация является грозным признаком внутреннего дефолта. Уменьшение темпов роста внешнего долга и небольшое уменьшение его объёма, по-видимому, являлось макияжем для рейтинговых агентств и иностранных инвесторов с целью дальнейшего привлечения иностранных кредитов.

Социально-экономические последствия наращивания государственного долга можно представить, если обратиться к таблице 6.

В таблице 6 представлены следующие параметры: валовой внутренний долг (ВВД) Украины, отношение ВВД к ВВП, приведённым на душу населения, а также разность между ВВД и ВВП, приведённым на душу населения. Важно отметить, что внутренний долг Украины не входит в ВВД, а внешний долг является частью ВВД, представляющей обязательства Правительства и Национального банка Украины; остальная часть ВВД Украины связана с долгами коммерчески банков и корпораций.

Как следует из представленных данных, ВВД Украины, стабильно возрастает в течение всего исследуемого периода. Возрастает и достигает постоянного значения отношение ВВД/ВВП; данное значение составляет около 80 \% от ВВП.

Совершенно аналогичная тенденция наблюдается для параметра ВВД/ВВП, приходящихся на душу населения.

Особого внимания, по мнению автора, заслуживает величина ВВД/ВВП, приходящихся на душу населения. Экономический смысл указанной ве-

Таблица 6.

Долговая нагрузка Украины за период с 2010 по 2014 г.*

\begin{tabular}{|c|c|c|c|c|c|c|}
\hline Показатель & $\mathbf{2 0 0 8}$ г. & $\mathbf{2 0 0 9}$ г. & $\mathbf{2 0 1 0}$ г. & $\mathbf{2 0 1 1}$ г. & $\mathbf{2 0 1 2}$ г. & $\mathbf{2 0 1 3}$ г. \\
\hline ВВД, млрд.долл. & 79.995 & 101.659 & 103.396 & 117.343 & 126.236 & 135.065 \\
\hline ВВД/ВВП, \% & 56 & 56,7 & 88,3 & 86,8 & 76,4 & 76,6 \\
\hline (ВВД/ВВП) на душу населения & 56 & 56,7 & 88 & 86 & 76,4 & 77 \\
\hline (ВВП- & 1,3535 & 1,6844 & 0,299 & 0,416 & 0,857 & 0,905 \\
\hline
\end{tabular}

* Сайт министерства финансов Украины: minfin.gov.ua 
Революции / Revolutions

личины - это показатель уровня жизни населения Украины после того, как своевременно и в полном объёме государство выполнит все свои обязательства перед иностранными кредиторами.

Как следует из представленных результатов, указанный параметр имел тенденцию как к падению: с 1.353 долл. в 2007 г. до 299 долл. в 2010 г., так и к росту до 905 долл. в 2013 г.

Кроме того, не стоит забывать ещё и про внутренние обязательства, которые также необходимо выполнять.

Таким образом, долговая политика Украины, во многом определявшая социальное и экономическое развитие страны, являлась чрезвычайно зависимой от конъюнктуры мирового рынка капиталов. Уровень жизни населения был чрезвычайно уязвим к любым требованиям кредиторов.

Одним из исторических, стратегических партнёров Украины в течение всего времени существования её в качестве независимого государства была и есть в настоящее время Россия. Ведь как бы не складывалась мировая политическая конъюнктура, народы России и Украины являются именно братскими, а не только экономическими и финансовыми партнёрами.

Какова же роль России в кредитовании экономики Украины? По словам Президента РФ, совокупный долг украинских предприятий перед Россией, по состоянию на 2013 г., составляет 30 млрд. долл.

Общая структура долга Украины перед РФ представлена рисунке 1.

Как следует из рисунка, задолженность украинских предприятий перед ведущими российскими банками составила 28 млрд. долл. Из них: 20 млрд. долл. в виде валютных кредитов, 280 миллиардов рублей (эквивалентно 8 млрд. долл.) в виде рублёвых кредитов. Кроме того, импорт российских энергоносителей обошёлся Украине примерно в 2 млрд. долл.

Состав российских кредиторов украинских предприятий представлен на рисунке 2 .

Как следует из рисунка, состав кредиторов украинских предприятий представлен следующими российскими крупнейшими банками: Газпромбанком, Сбербанком, ВЭБ и ВТБ.

Весьма важным обстоятельством является то, что внешний государственный долг Украины, по состоянию на ноябрь 2013г., составил 26,3 млрд. долл.

Это означает, что долг Украины перед РФ по своему объёму превысил внешний государственный долг. Долг Украины перед российскими кре-

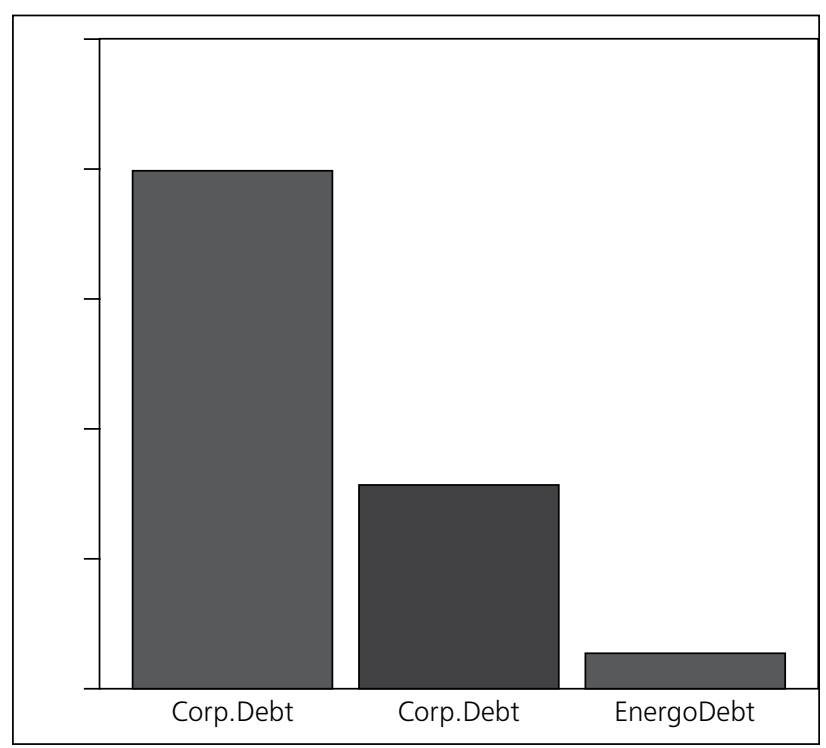

Рис. 1. Общая структура долга Украины перед РФ.

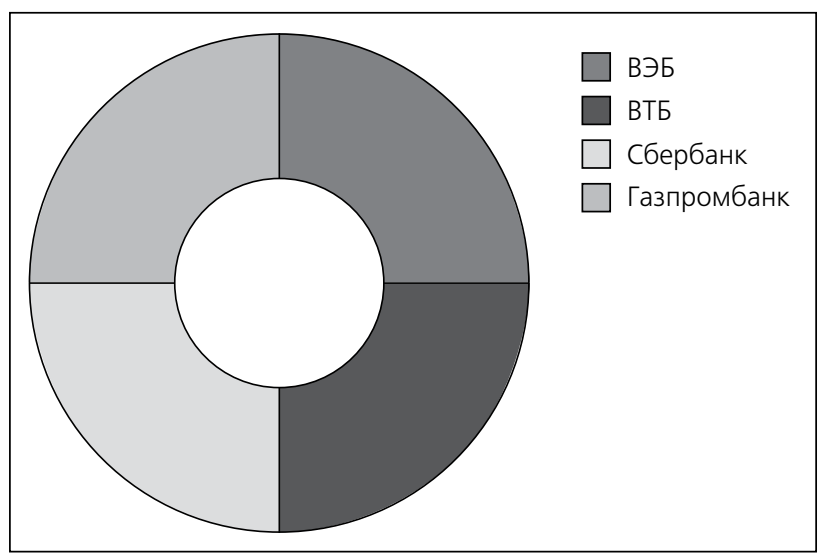

Рис. 2. Состав кредиторов украинских предприятий.

диторами составляет половину от общего государственного долга.

Тем не менее, по словам Президента РФ, Россия будет работать с Украиной по урегулированию этой задолженности, а также по газовым долгам, вне зависимости от решения Киева о возможной евроинтеграции. Ответ украинской стороны, представленный Премьер-министром, состоял лишь в том, что у Киева нет никаких договоренностей с Россией о новых кредитах ${ }^{3}$.

Таким образом, экономические интересы России на Украине в финансовом аспекте представлены в виде крупной системы долгов со стороны Украины.

\footnotetext{
3 http://ria.ru/economy/20131126/979892067.html; http://
} www.interfax.ru 


\section{Международные отношения / International Relations}

Проведённый анализ позволяет сделать заключение о том, что экономическое развитие Украины, во-первых, не является динамичным и устойчивым. Экономика, по сути, сконцентрирована на том, чтобы брать долги с целью погашения текущих обязательств, заботясь лишь о кредитных рейтингах и не заботясь о реальном экономическом развитии. Во-вторых, развитие экономики Украины, по состоянию на 2013 г., чрезвычайно неустойчиво и находится колоссальной зависимости от внешнего локального и глобального негативного воздействия. Это немедленно сказывается на уровне жизни населения, создавая угрозу социально-экономических потрясений. Именно такая ситуация, по мнению автора, и сложилась в декабре 2013 г. Таким образом, налицо экономические предпосылки внутриполитического кризиса на Украине, возникшего в декабре 2013 г.

Неэффективная, убыточная экономика Украины в течение исследуемого периода времени кредитовалась банками из России, ЕС и США. Доля участия российских банков в экономической системе Украины весьма высока. Значит, любое (!) экономическое решение Украины затрагивает и экономические интересы России.

В начале зимы 2013 года глава Украины дал сигнал на сближение и сотрудничество с Евросоюзом, одновременно проявляя интерес и к России. Простота и сложность ситуации состоит в том, что Украина встала перед проблемой выбора приоритетного союзника.

Это проявилось в стремлении примкнуть либо к Евросоюзу с малореализуемой перспективой вступления в него на правах потенциального полноправного участника, либо во вступлении Украины в Таможенный союз, в котором лидирующую позицию заняла Россия, отводя при этом Украине роль безусловного полноправного партнёра. Очевидно, что окончательное решение примкнуть к одной из сторон является одновременно решением об отдалении от другой стороны. В результате, как блок ЕС-США, так и Россия настороженно отнеслись к нерешительности и, очевидному двусмысленному поведению руководства Украины.

Внутри же Украинского государства резко активизировались два политических течения: одно из них, представлено силами, выступающими за интеграцию с ЕС при поддержке США; второе - вы- ступает за более тесное сотрудничество с Россией. Представители второго течения отдают и себе и окружающим отчёт в том, что подрыв экономических отношений с Россией, к чему, похоже, призывают Украину с Запада, чреват гораздо более серьёзными социально-экономическими последствиями, чем ослабление отношений с ЕС. Важно отметить, что о сроках и условиях вступления Украины в Евросоюз на правах полноправного участника вопрос не поднимался. Кроме того, какова перпектива подобного решения со стороны ЕС?

Попробуем сопоставить ряд фактов. Экономика Украины слаба, как, например, слаба экономика Греции - участника ЕС. Да, в страны Евросоюза оказали в своё время помощь этой стране. Но с каким трудом принимались решения о финансовой помощи Греции, какие непопулярные решения принимало руководство Греции по отношению к собственным гражданам. Однако преодолеть финансовые трудности грекам не удаётся до сих пор.

Будет ли выступать ЕС в роли «экономического реаниматолога» Украины в случае их потенциальной интеграции? Этот вопрос оставлю без ответа, поскольку даже если помощь и последует, то хватило бы её на полноценное и безусловное решение экономических проблем Украины? При существующих экономических проблемах внутри ЕС появление ещё одного дотационного и экономически неэффективного субъекта привело бы только к усугублению этих проблем.

С другой стороны, в условиях загнанной и буксующей экономики Украины, нарушение экономических отношений с Россией, очевидно, приведёт к её полному коллапсу.

Ведь именно РФ обеспечивает Украину энергоресурсами, причём по льготным, отличающимся от мировых, ценам. Именно Россия является крупнейшим торговым партнёром Украины. Кроме того, через Украину проходит и транзит нефти и газа в Европу, что приносит дополнительные средства в бюджет Украины, и именно ЕС заинтересован в том, чтобы поток энергоресурсов из РФ проходил бесперебойно.

Таким образом, в ноябре-декабре 2013 г. начал происходить открытый захват сфер влияния РФ на Украине путём политического манипулирования антироссийскими силами внутри Украины.

\section{Библиография}

1. Сайт Международного банка: www.worldbank.org 
2. Сайт Международного валютного фонда: www.imf.org

3. Сайт министерства финансов Украины: minfin.gov.ua

4. http://ria.ru/economy/20131126/979892067.html

5. http://www.interfax.ru

6. Бородинов Е.Н. Причины и следствия государственного переворота на Украине // NB: Международные отношения. - 2014. - 3. - C. 36-59. DOI: 10.7256/2306-4226.2014.3.11501. URL: http://www.enotabene.ru/wi/article_11501.html

7. Гушер А.И. Политический кризис на Украине // NB: Международные отношения. - 2014. - 3. - C. 15-26. DOI: 10.7256/2306-4226.2014.3.11502. URL: http://www.e-notabene.ru/wi/article_11502.html

8. Манойло А.В. Вооруженный мятеж в Украине: волна цветных революций идет на Россию // NB: Международные отношения. - 2014. - 3. - C. 27-35. DOI: 10.7256/2306-4226.2014.3.11498. URL: http:// www.e-notabene.ru/wi/article_11498.html

9. Манойло А.В. Вооруженный мятеж в Украине может стать для России последним тревожным звонком // NB: Международные отношения. - 2014. - 2. - C. 24-37. DOI: 10.7256/2306-4226.2014.2.11137. URL: http://www.e-notabene.ru/wi/article_11137.html

10. Манойло А.В. Геополитическая картина современного мира // Национальная безопасность / поtа bene. - 2013. - 5. - C. 149-155. DOI: 10.7256/2073-8560.2013.5.9394.

\section{References}

1. Sait Mezhdunarodnogo banka: www.worldbank.org

2. Sait Mezhdunarodnogo valyutnogo fonda: www.imf.org

3. Sait ministerstva finansov Ukrainy: minfin.gov.ua

4. http://ria.ru/economy/20131126/979892067.html

5. http://www.interfax.ru

6. Borodinov E.N. Prichiny i sledstviya gosudarstvennogo perevorota na Ukraine // NB: Mezhdunarodnye otnosheniya. - 2014. - 3. - S. 36-59. DOI: 10.7256/2306-4226.2014.3.11501. URL: http://www.e-notabene. $\mathrm{ru} /$ wi/article_11501.html

7. Gusher A.I. Politicheskii krizis na Ukraine // NB: Mezhdunarodnye otnosheniya. - 2014. - 3. - S. 15-26. DOI: 10.7256/2306-4226.2014.3.11502. URL: http://www.e-notabene.ru/wi/article_11502.html

8. Manoilo A.V. Vooruzhennyi myatezh v Ukraine: volna tsvetnykh revolyutsii idet na Rossiyu // NB: Mezhdunarodnye otnosheniya. - 2014. - 3. - S. 27-35. DOI: 10.7256/2306-4226.2014.3.11498. URL: http:// www.e-notabene.ru/wi/article_11498.html

9. Manoilo A.V. Vooruzhennyi myatezh v Ukraine mozhet stat' dlya Rossii poslednim trevozhnym zvonkom // NB: Mezhdunarodnye otnosheniya. - 2014. - 2. - S. 24-37. DOI: 10.7256/2306-4226.2014.2.11137. URL: http://www.e-notabene.ru/wi/article_11137.html

10. Manoilo A.V. Geopoliticheskaya kartina sovremennogo mira // Natsional'naya bezopasnost' / nota bene. 2013. - 5. - S. 149-155. DOI: 10.7256/2073-8560.2013.5.9394. 